\title{
SOME EPIDEMIOLOGICAL AND PREVENTIVE MEASURES FOR CASEOUS LYMPHADENITIS IN SHEEP AT QUALIN DISTRICT
}

\author{
Dalal Y. Rizk, Yamen M. Hegazy, Atef F. Orieby and Magdy H. AL-Gaabary \\ Department of Animal Medicine, Faculty of Veterinary Medicine, \\ Kafrelsheikh University (Egypt).
}

\begin{abstract}
Caseous Lymphadenitis (CLA) is a contagious chronic disease of small ruminants caused by a gram-positive aerobic facultative micro organism. In this study, a cross sectional study was carried out to estimate CLA prevalence among sheep population in Qualin district. Out of 315 examined sheep, 10\% were showed the clinical signs of CLA. Serologically, 144 sheep were examined by ELISA which resulted in a true seroprevalence of 61\% (95\% CI: 53-69\%). evaluation of application of Betadine on wounds and using of shearing machine as control measures for CLA in sheep flocks resulted in the decrease the prevalence of CLA from $9.3 \%$ to $2.6 \%$ in an infected flock. In conclusion, CLA is a endemic disease in the study area at high levels of prevalence and official control measures has to be undertaken to minimize its huge economic losses.
\end{abstract}

\section{INTRODUCTION}

Caseous Lymphadenitis (CLA) is a contagious chronic disease of small ruminants caused by a gram-positive aerobic facultative coocobacilli; Corynebacterium pseudotuberculosis (Fontaine and Baird 2008). CLA is of significant economic concern for sheep husbandry due to reduced wool, meat and milk yield, loss of fertility, culling of affected animals, condemnation and downgrading of affected carcass at slaughter and meat inspection (Williamson 2001; Guimaraes et al. 2011). 
Two forms have been described for CLA; external and internal forms. External form characterized by abscess in superficial lymph node and subcutaneous tissue. Internal form characterized by internal abscess located in the internal organs especially the lung, liver, kidney and bronchial, lumber lymph node with animal wasting: thin ewe syndrome (Ivanovic et al. 2009; Oreiby et al. 2013).

Clinical signs and post-mortem of CLA have diagnostic values but the confirmation of diagnosis generally achieved by the bacterial culture, serological and nucleic acid based detection methods (Ilhan 2013). The most popular serological test for CLA is ELISA using different antigenic components including PLD (extracted from culture supernatant or in recombinant form rPLD) (Sting et al. 2012; Oreiby 2015).

The sources of infection to healthy animals are abscesses discharging from ruptured external lymph nodes which contaminate the shearing and feeding equipment which are responsible for spread of the organism (O'Reilly et al. 2008). There are many risk factors for CLA spread such as; the lacking of sanitary measures (Chirino-Zarraga et al. 2006).

Control of CLA has some element; using penicillin at day zero of shearing in addition to disinfection of shearing instrument and wounds greatly reduced the disease occurrence (Al-Gaabary et al. 2009). A routine palpation of the superficial lymph nodes in sheep, for detection the infected animals. And shearing equipment and supplies should be routinely cleaned and disinfected before use. (Windsor 2011). 


\section{MATERIAL AND METHODS}

\section{Animals and clinical examination:}

A total of 315 sheep of different ages and sexs in Qualin district of Kafrelsheikh governorate were examined clinically for CLA. Out of the examined animals, 75 belonged to governmental flock and 265 animals belonged to private flocks. All animals were subjected to careful clinical examination according to (Rosenberger et al. (1979).

\section{Bacteriological examination:}

A- Samples for bacteriology examination:

Aspiration: Closed abscessaited superficial lymphnods were aseptically aspirated using sterile syringe, and after disinfection of the skin by Betadine.

Swabbing: pened abscessaited superficial lymphnodes were deeply swabbed using sterile cotton swabs.

Pus sample were transferred to laboratory on ice for bacterial isolation and identification.

\section{B- Isolation and identification:}

Pus samples were cultured on 10\% sheep blood agar and brain heart infusion agar media then incubated aerobically-at $37^{\circ} \mathrm{C}$ enriched with $5 \% \mathrm{Co}_{2}$ for 48 hours according to the method described by (Bailey and scott1990). The resultant colonies were examined for consistency, colour, type of hemolysis and their ability to be pushed across the agar surface (Selim, 2001). Bacterial films were prepared, fixed and stained by Gram's stain and examined microscopically. Stain reaction, shape and arrangement of the bacterial cells and the presence of were investigated. The confirmation of identification was done using PCR for the isolated colonies (unpublished work). 


\section{Serological examination:}

Blood samples were collected from 149 examined animals in $10 \mathrm{~cm}$ syringe and were sent to lab. Serum were separated by centrifugation and kept in $-20^{\circ} \mathrm{C}$ till used for ELISA according to (Menzies et al. (2004) with some modifications. The antigen used in this serological test is the exotoxin prepared from local strain of $C$. pseudotubercullosis by the same authors of this article (unpublished data).

\section{Statistical analysis:}

The prevalence of clinical CLA among examined animals was estimated as followings:

$\mathbf{P}=($ Number of animals with superficial abscesses/Number of examined animals) $\quad$ x 100 Thrusfield M (2007).

While the apperent seroprevalence of CLA was estimated as following:

$\mathbf{A P}=($ Number of animals seropositive to CLA using ELISA/Number of examined animals against CLA using ELISA) x 100 Thrusfield $M(2007)$

The true seroprevalence of CLA was estimated as following: $\mathbf{T P}=\mathrm{AP}+\mathrm{Sp}-1 / \mathrm{Se}+\mathrm{Sp}-1 \quad$ Thrusfield $\boldsymbol{M}$ (2007).

Where TP is the true seroprevalence, Se is the sensitivity of ELISA (81\%) and $\mathrm{Sp}$ is the specificity of ELISA (98\%) (Sting, 2012)

The confidence interval for the TP was estimated as following: $C I=p \pm Z * \sqrt{\frac{p^{*}(1-p)}{n}}$ Thrusfield M (2007) 


\section{Preventive measures:}

The governmental flock was subjected to wound disinfection using betadine solution in all wounds produced during shearing. Around 35 animals were injected with Penicillin G Benzathin at the searing time. The prevalence of CLA was $8 \%$ before application of this preventive measures. The flock was followed up for 1 year. Evaluation of the efficacy of the preventive measures was done on the basis of the appearance of the new cases within a year post management and estimating the disease prevalence.

Using of shearing machine and shearing scissors to assess the role of shearing machine in sheep flocks in decreasing the number of wounds during shearing process in sheep flocks.

All statistical analysis were carried out using chi square test and fisher's test on SPSS V 19.

\section{RESULTS}

Out of 315 examined animals, 33 animals were showed the clinical signs mentioned below with a clinical prevalence of (10.47\%). Clinical signs showed superficial abscesses of distinct variation in size which ranged from bean's size up to orange size (Figure 1,2). Abscesses contents varied in consistency from milk-like fluid to creamy or even hard caseous materials and the color was almost white and occasionally greenish in some cases. Wool over lesions was usually lost except in few cases. Others showed chronic ill-thrift and poor condition animals showed reproductive disorders.

$\overline{\text { Kafrelsheikh Vet. Med. J. Vol. } 13 \text { No. } 2 \text { (2015) }}$ 


\section{The number and distribution of lesions:}

Concerning the number of lesions, $93.93 \%, 6.06 \%$ and $3.03 \%$ of animals showed single, double and multiple lesions, respectively. Parotid lymph nodes were the most commonly affected (followed by prescapular, sub maxillary, mandibular, prefemoral, and popliteal ). Closed lesions were seen in $78.79 \%$ of sheep and opened lesions were in $21.21 \%$ of cases.

\section{The clinical prevalence by sex and age:}

The distribution of CLA by age and sex is shown in tables $(1,2)$. Females and animals aged more than 2 years were significantly affected with CLA more than other male and young animals.

Table (1): Clinical prevalence of CLA in relation to age.

\begin{tabular}{|c|c|c|c|}
\hline \multirow{2}{*}{ Age } & \multicolumn{3}{|c|}{ Number of animal } \\
\hline & Examined & Affected & Prevalence \\
\hline Under 1 year & 33 & 3 & 9.09 \\
\hline $1-2$ years & 65 & 1 & 1.53 \\
\hline Over 2 years & 217 & 29 & 13.36 \\
\hline
\end{tabular}

P-value $<0.011$

Table (2): Clinical prevalence of CLA in relation to sex

\begin{tabular}{|c|c|c|c|}
\hline \multirow{2}{*}{ Sex } & \multicolumn{3}{|c|}{ Number of animal } \\
\hline & Examined & Affected & Prevalence \\
\hline Male & 49 & 1 & 2.04 \\
\hline Female & 266 & 32 & 12.03 \\
\hline
\end{tabular}

P-value $<0.04$

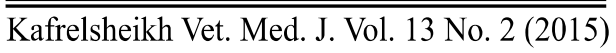




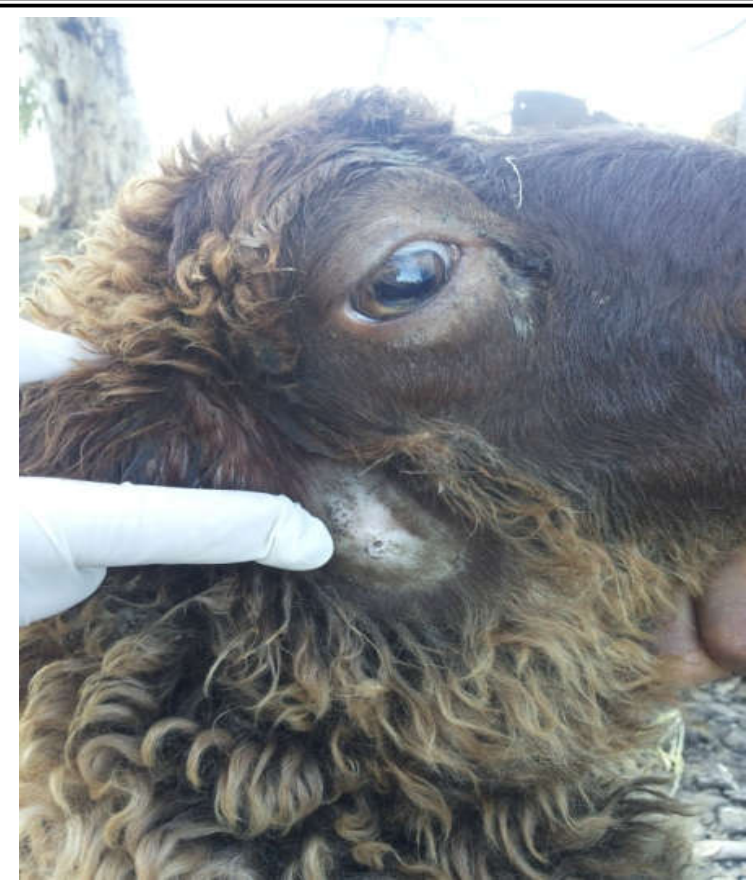

Fig. (1): Sheep with CLA showed an abscess in parotid lymphnode

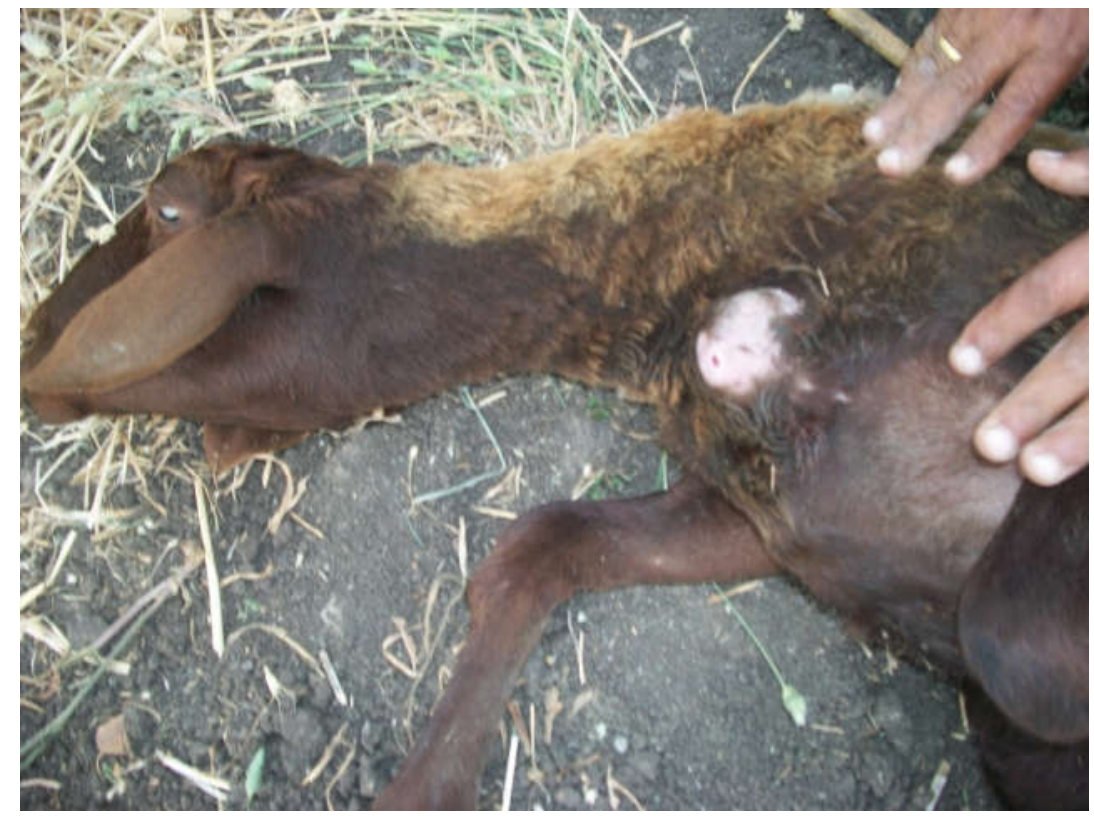

Fig. (2): Sheep with CLA showed an abscess in prescapular lymphnode

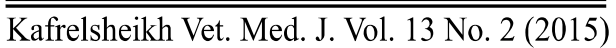




\section{Results of Seroprevalence:}

Out of 144 examined animals, 76 were serologically positive with AP of $52.7 \%$.

The true prevalence was estimated at $61 \%$ and $\mathrm{CI}=95 \%$. ( 53 $69 \%$ ). The comparison between clinical and serological prevalence is shown in table 3.

Table (3): The comparison between clinical and serological prevalence

\begin{tabular}{|c|c|c|c|}
\hline Condition & Total examined number & Number of positive & $\%$ \\
\hline Clinically affected sheep & 27 & 17 & $63 \%$ \\
\hline Apparently health & 117 & 59 & $50 \%$ \\
\hline Total & 144 & 76 & $52.7 \%$ \\
\hline
\end{tabular}

The distribution of seroprevalence by age and sex showed in tables $(4,5)$.

Table (4): Seroprevelance of CLA in relation to age

\begin{tabular}{|c|c|c|c|}
\hline \multirow{2}{*}{ Age } & \multicolumn{3}{|c|}{ Number of animal } \\
\hline & Examined & Affected & Prevelance\% \\
\hline Under 1 year & 13 & 2 & 15.38 \\
\hline $1-2$ years & 20 & 9 & 45 \\
\hline Over 2 years & 111 & 65 & 58.55 \\
\hline
\end{tabular}

P-value $<0.01$

Table (5): Seroprevelance of CLA in relation to sex

\begin{tabular}{|c|c|c|c|}
\hline \multirow{2}{*}{ Sex } & \multicolumn{3}{|c|}{ Number of animal } \\
\hline & Examined & Affected & Prevalence\% \\
\hline Male & 18 & 7 & 38.88 \\
\hline Female & 126 & 69 & 54.76 \\
\hline
\end{tabular}

P-value $<0.21$

$\overline{\text { Kafrelsheikh Vet. Med. J. Vol. } 13 \text { No. } 2 \text { (2015) }}$ 
Some Epidemiological And Preventive Measures For ...

\section{Resultes of bacteriological examination:}

Corynebacterium pseudotuberculosis was isolated from clinical cases and identified by PCR (unpublished work). Figure 3 showed Gram positive Chinese letter arranged coocobacilli.

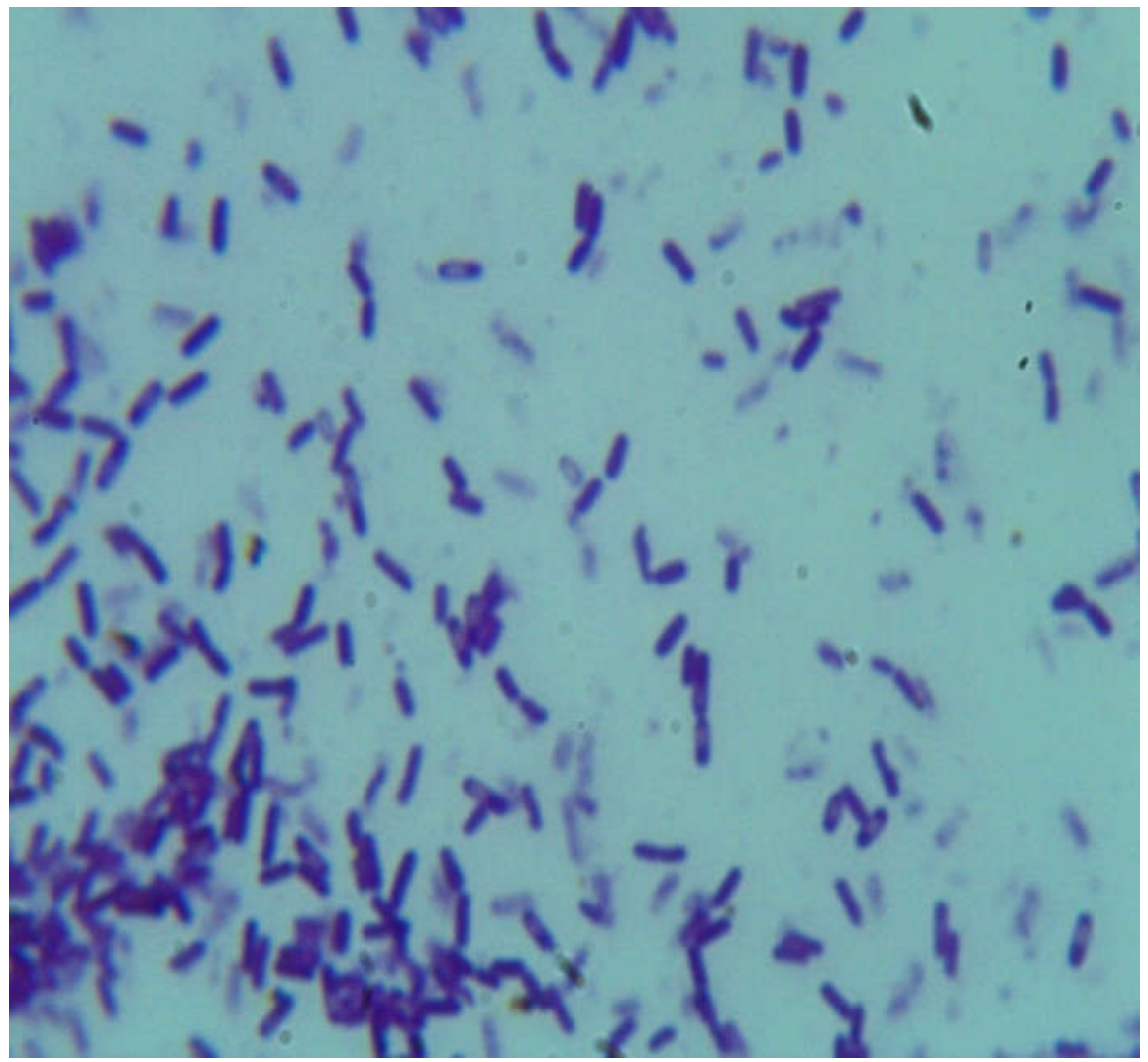

Fig. (3): Gram positive Chinese letter arranged coccobacilli

\section{Results of control measures}

A- The clinical prevalence of CLA in the examined flock was reduced from $9.3 \%$ to $2.6 \%$ following the application of control measures.

B- The avarege number of wounds produced by machine was 1.25 in wound/ animal in comparison to 5.2 with scissors. 


\section{DISCUSSION}

Caseous lymphadenitis is a worldwide chronic infectious disease of small ruminants characterized by formation of pyogranulomas mainly in superficial lymph nodes and rarely in visceral lymph nodes and organs (Paule et al., 2004 and Baird and Fontaine, 2007).

CLA is an endemic disease among small ruminants in Egypt. Several studies were carried out to investigate its prevalence among sheep population (Al-Gaabary, and El-Sheikh 2002; Oreiby et al. 2013).

In this study we aimed at examination of CLA prevalence in an area of high density of sheep population also we aimed at examine some control measures which could help in minimization of prevalence of the disease.

In this study the clinical prevalence was found to be $10.47 \%$ among examined sheep and this agree with finding of (Baird et al. 2004,AlGaabary et al. 2009) on the other hand (90\%) Kuria and Holstad (1989) fonnded that the prevalence reaches to $90 \%$ he difference of geographic area, type of breeding and animal breed. our result may be related to most of infected animals don't showed apparent clinical signs and this is why also we did the serological examination.

Serological examination showed that the seroprevalence of CLA is 61\% (95\%CI: 53- 69) on the other hand (Guimarães et al 2009) recorded that $70.9 \%$ (95\% confidence interval (CI): 64.7-77.0\%). The high seroprevalence of CLA in the study isrevealed the contagious nature of CLA in infected flock. This highlights the importance of examination of newly introduced animals to flocks and the importance of hyegenic

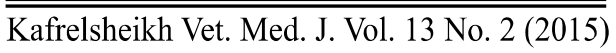


measures to prevent spread of infection. Also this result showed the reason of ignorance of sheeperd and farmer to CLA as they don't see more than around $10 \%$ of infected animals.

Also our results of very high seroprevalence declared the importance of application of control measures against CLA. This high prevalence means that there is a huge silent production loss and this may be the reason of reproductive failure and ill thrift of huge number of sheep belonged to sheeperd. So we suggest a national control programe for CLA to be able to reduce the economic losses from CLA.

In this study the lesions size were found variant in size, from beans size to orange size and this depends on stage of the disease potency of exotoxins and immunity. Our results agree with Gaabary, and ElSheikh 2002; Al-Gaabary et al. 2009, 2010; Oreiby et al. 2013, 2014). Closed lesions were seen in $78.79 \%$ of sheep and opened lesion were in $21.21 \%$ of cases. This is agree with (Oreiby 2014).

In a relation to sex prevalence there was a significant differenence between males and females that mean the females were higher $75.57 \%$ than males $66.66 \%$, this because the females live more longer than males so the chance of infection is high. this is agree with (Al-Gaabary et al. 2009) this is disagree with (Nadim and Farid et al. 1973; Zaitoun and Ali 1999a; Oriby et al. 2013) but the latter found in significant differenence similar to our seroprevalence study.

In this study the prevalence according to age were 9.09, 1.53, 13.36 at ages of under 1 year, 1-2 years and Over 2 years, respectively. This showed that the prevalence was higher in the age group more than 2 years, followed by less than one year and the age group from 1-2 years. 
Inspite that CLA is non age related disease (Al-Gaabary et al. 2009, Oreiby et al 2013), our results seems to not be biased and this is because normally aged animals has more chance for infection and showing CLA.

The highest percentage of parotid lymph node infection give an indication that ingestion, shearing practices or head butting have a considerable role in transmission of CLA in sheep.

application. One of this preventive measures is the usage of antiseptic solution with The basic element applied for prevention of CLA with low cost, and easily antibiotic after shearing. The preventive measure was able to decrease the prevalence of CLA from $9.3 \%$ to 2.6 $\%$ in an infected flock. The second element of control measure is the usage of shearing machine instead of scissors which was able to reduce the number of wounds with subsequent decrease the likelihood of infection to new animals. Our results agree with and (AlGaabary and ElSheikh 2002; Al-Gaabary 2009).

\section{REFERENCES}

- Al-Gaabary, M.H., El-Sheikh, W.M.A., (2002): Epidemiological, clinical and preventive studies on caseous lymphadenitis in sheep and goats at Gharbia governorate. In: 10th Sci. Cong. Fac. Vet. Med., Assiut University, Egypt, pp. 402-417.

- Al-Gaabary,M. H. and Osman, S. A. and Oreiby, A. F.(2009): Caseous lymphadenitis in sheep and goats: Clinical, epidemiological and preventive studies Small Ruminant Research 87: 116-121. 
- Al-Gaabarya, M. H.; Osmana, S. A.; Ahmed, M. S. and Oreiby, A. F.(2010): Abattoir survey on caseous lymphadenitis in sheep and goats in Tanta, Egypt Small Ruminant Research 94: 117-124.

- Baird, G.; Synge, B. and Dercksen, D. (2004): Survey of caseous lymphadenitis seroprevalence in British terminal sire sheep breeds. Veterinary Record. 154(16): 505-506.

- Baird, G.J. and Fontaine, M.C. (2007): Corynebacterium pseudotuberculosis and its role in ovine caseous lymphadenitis . J . Comp. Path. 137: 179-210.

- Bailey, A., Scott, S. (1990): Diagnostic Microbiology, 8th ed. C.V. Mosby Company, St. Louis.

- Chirino-Zárraga, C., Scaramelli, A., Rey-Valeirón, C., (2006): Bacteriologicalcharacterization of Corynebacterium pseudotuberculosis in Venezuelangoat flocks. Small Rumin. Res. 65, 170-175.

- El-Tahawy, A.S. (2010): The prevalence of selected diseases and syndromes affecting Barki sheep with special emphasis on their economic impact.

- Fontaine, M. C. and Baird, G. J. (2008): Caseous lymphadenitis. Small. Rumin. Res. 76:42-48.

- Guimaraes, A. S.; Seyffert, N.; Bastos, B. L.; Portela, R. W. D.; Meyer, R.; Carmo, F. B.; Cruz, J. C. M.; Mcculloch, J. A.; Lage. A. P.; Heinemann, M. B.; Miyoshi, A.; Azevedo, V. and Gouveia, A. M. G.(2009): Caseous lymphadenitis in sheep flocks of the state of Mina Gerais, Brazil: Prevalence and management surveys. Small Rumin Res 87: 86-91. 
- Guimaraes, A.S.; Carmo, F.B.; Pauletti, R.B.; Seyffert, N.; Ribeiro,D.; Lage, (2011): Caseous lymphadenitis: epidemiology diagnosis, and contro Institute of Integrative Omics and Applied Biotechnology Journal, 2 (2), 33-43.

- Ivanovic, S.; Zutic, M.; Pavlovic, I. and Zujovic, M. (2009): (Caseous Lymphadenitis) in goats. Biotechnology in animal husbandary. 25 (5\6) 999-1007.

- Ilhan, Z. (2013): Detection of Corynebacterium pseudotuberculosis from sheep lymph nodes by PCR.Revue. Med. Vet .164 (2): 60 -66.

- Kuria, J.K., Holstad, G., (1989): A seroepidemiological investigation of Corynebacterium pseudotuberculosis infection in sheep flocks in southern Norway. Acta Vet. Scand. 30, 107-108.

- Menzies, P. I.; Hwang, T. I. and Prescolt, J. F. (2004): Comparison of an interferon gamma to phospholipase D enzyme linked immunosorbent assay for diagnosis of Corynebacterium pseudotuberculosis infection in experimentally infected goats. Vet. Microbiol. 100: 129-137

- Nadim, M.A. and Farid, A. (1973): Caseous lymphadenitis in sheep in Egypt, bacteriological studies on the isolated $C$. ovis strains, trials for treatment both in vitroandin vivo. J. Egypt. Vet. Med. Assoc. 33:19-43.

- Selim, S.A., (2001): Oedematous skin disease of buffalo in Egypt. Journal of Veterinary Medicine. B, Infectious Diseases and Veterinary Public Health 48:241-258. 
- Oreiby, A. F.; Osman, S. A.; Yamen, M. Hegazy, Y. M.; Ghanem,Y.A. and Al-Gaabary, M. H. (2013): Caseous lymphadenitisin small ruminant: descriptive, epidemiological clinical studies. Kafrelsheikh Vet. Med. J. Vol. 11 No. 1 (41-61).

- Oreiby, A. F.; Hegazy, Y. M.; Osman, S. A; Ghanem, Y. M and Al-Gaabary . M. H. (2014): Caseous lymphadenitis in small ruminants in Egypt. Clinical, epidemiological and prophylactic aspects Tierärztl Prax; 42: 271-277.

- Oreiby, A. F. (2015): Diagnosis of caseous lymphadenitis in sheep and goat. Small Ruminant Research 123 : 160-166.

- O’Reilly, K.M., Green, L.E., Malone, F.E., Medley, G.F., (2008): Parameter estimation and simulations of a mathematical model of Corynebacteriu pseudotuberculosis transmission in sheep. Prev. Vet. Med. 83, 242- 259.

- Paton, M. W. (2010): The epidemiology and control of Caseous Lymphadenitis in Australian sheep flocks. Ph. D. Thesis, School of Veterinary and Biochemical Sciences. Murdoch University.

- Paule, B.J.A., Meyer, R., Mouracosta, L.F., Bahia, R.C., Carminati, R., Regis, L.F., Vale, V.L.C., Freire, S.M., Nascimento, L., Schaer, R., Azevedo, V. (2004): Three phase partitioning as an efficient method for extraction concentration of immunoreactive excreted secreted proteins of Corynebacterium pseudotuberculosis. Protein Expr. Purif. 34: 311-316. 
- Rosenberger, G.; Dirksen, H. D.; Grunert, E.; Krause, D.; Stober, M. and Mack, R. (1979): Clinical examination of cattle 1st edition, Verlag Paul Parrey, Berlin and Hamburg.

- Sting, R., Wagner, B., Sari-Turan, A., Stermann, M., Reule, M., Eichner, M., Beyer, W., (2012): Serological studies on Corynebacterium pseudotuberculosis infections in goats in BadenWuerttemberg (Germany) andseroreactions on antigens used for newly developed enzyme-linkedimmunosorbent assays (ELISA). Berl. Munch. Tierarztl. Wochenschr.125, 67-75.

- Thrusfield, M., (2007): Veterinary epidemiology. Wiley-Blackwell.

- Windsor, P. A. (2011): Control of Caseous Lymphadenitis. Vet. Clin. Food Anim. 27: 193-202.

- Williamson, L. H. (2001): Caseous lymphadenitis in small ruminants. Vet. Clin. North Am. Food Anim. Pract. 17: 359-371.

- Zaitoun, A.M., Ali, H.S. (1999): Clinical and experimental pseudotuberculosis on a multiple ages sheep and goats flock with control trials via treatment and BCG vaccination. Assiut Vet. Med. J. 42, 239-259 